\title{
Pemahaman Materi Bangun Ruang dengan Berbantuan GeoGebra
}

\author{
1Delia Dwi Arsita, 2Mufidatul Ummah Nurul Hidayah, ${ }^{3}$ Surya Sari Faradiba \\ 1,2,3Program Studi Pendidikan Matematika, FKIP, Universitas Islam Malang \\ 1Email:delia_dwia@yahoo.com
}

\begin{abstract}
This study has purpose to explore the use of GeoGebra in understanding concept of building up space. It is based by the fact that the ability to understand building space six grade elementary school in the city of Malang is still low. based on research conducted in the oddest semester of 2019/2020 obtained at least 6 of 10 elementary school students in one of the private elementary schools in Malang city have difficulty to understanding the concept of building space. In this case, it can be seen that the ability of understanding material build space is still not honed well. This research is a qualitative research, the type of this study is case study. The instrument in this study is a test problem related to the building space, and interview guidelines. In this study, the description of data analysis and meaning interpretation of finding is using text analysis. The results show that the subjects easier to understand the concept of building space with GeoGebra, because it uses the subject GeoGebra can see the building in 3D.
\end{abstract}

Keyword: GeoGebra, Geometry

\begin{abstract}
Abstrak: Penelitian ini bertujuan untuk mengeksplorasi penggunaan GeoGebra dalam memahami konsep bangun ruang. Hal ini dilatar belakangi oleh fakta bahwa kemampuan memahami bangun ruang, kelas VI SD di Kota Malang masih rendah. Berdasarkan penelitian yang dilakukan pada semester ganjil 2019/2020 didapat setidaknya 6 dari 10 siswa Sekolah Dasar di salah satu SD Swasta di Kota Malang mengalami kesulitan dalam memahami konsep materi bangun ruang. Dalam hal ini, dapat dilihat bahwa kemampuan pemahaman materi bangun ruang masih belum terasah dengan baik. Penelitian ini merupakan penelitian kualitatif, dengan jenis penelitian yang digunakan adalah studi kasus. Instrumen dalam penelitian ini adalah soal tes terkait dengan materi bangun ruang, serta pedoman wawancara. Pada penelitian ini, deskripsi analisis data dan interpretasi makna temuan menggunakan analisis teks. Hasil penelitian menunjukkan bahwa subjek lebih mudah memahami konsep materi bangun ruang dengan berbantuan GeoGebra, karena dengan menggunakan GeoGebra subjek dapat melihat bangun ruang secara 3D.
\end{abstract}

Kata Kunci: GeoGebra, Bangun Ruang

\section{PENDAHULUAN}

Matematika merupakan ilmu universal yang mendasari perkembangan teknologi modern, mempunyai peran penting dalam berbagai disiplin dan memajukan daya pikir manusia (Kusuma \& Utami, 2017). Mata pelajaran Matematika dapat ditemukan dalam semua jenjang pendidikan untuk membekali peserta didik dengan kemampuan berpikir logis, analitis, sistematis, kritis, dan kreatif, serta kemampuan bekerja sama (Erleni \& Fitri, 2015). Menurut Permendiknas No. 22 Tahun 2006, tujuan pembelajaran matematika adalah memahami konsep matematika, menggunakan penalaran, melakukan manipulasi matematika, memecahkan masalah, mengomunikasikan gagasan untuk memperjelas keadaan atau masalah dan memiliki sikap menghargai kegunaan matematika dalam kehidupan. Dengan melakukan berbagai kegiatan yang terkait matematika, peserta didik 
dapat berlatih mengembangkan kemampuan diri dan pengetahuannya guna memecahkan masalah.

Salah satu materi matematika adalah geometri. Geometri berisi materi yang abstrak, bagi siswa yang memiliki kemampuan rendah dalam melakukan proses abstraksi maka mereka kurang tertarik dalam mengikuti pelajaran, dan kesulitan memahami konsep geometri (Kusuma \& Utami, 2017). Materi geometri yang membutuhkan pemahaman khusus adalah bangun ruang. Bangun Ruang adalah bagian ruang yang dibatasi oleh himpunan titik-titik yang terdapat pada seluruh permukaan bangun tersebut (Erleni \& Fitri, 2015). Menurut Subarinah (2006: 36) bangun ruang merupakan bangun geometri dimensi tiga dengan batas-batas berbentuk bidang datar atau bidang lengkung. Materi pada bangun ruang bersifat abstrak yang membuat siswa susah memahami. Salah satu upaya memvisualisasikan ide matematika, agar siswa benar-benar memahami, khususnya materi geometri membutuhkan strategi pembelajaran yang inovatif. Media inovatif dengan memanfaatkan TIK adalah media GeoGebra sebagai sumber belajar dan media pembelajaran (Japa, Suarjana, \& Widiana, 2017).

GeoGebra adalah aplikasi yang didesain khusus untuk materi pengajaran geometri dan algebra (aljabar). GeoGebra merupakan open source software dibawah GNU General Public License dan dapat diperoleh secara gratis di portal www.GeoGebra.org (Aryasuta, Eka, \& Sukew, 2014). Aminah (dalam (Hohenwater, 2008) menyatakan bahwa GeoGebra sebagai software dengan ide dasar mengabung geometri, aljabar, dan kalkulus yang dapat digunakan untuk belajar dan mengajar di tingkat SD, SMP, SMA, dan Universitas. Penggunaan GeoGebra membuat siswa dapat melihat dimensi tiga dari berbagai arah. Hal ini membuat aktivitas siswa lebih menarik karena memiliki pengalaman dalam mengamati perbedaan bangun dimensi tiga jika dilihat dari sudut yang berbeda (Kusuma \& Utami, 2017). Mengingat masih kurangnya pemahaman siswa terkait materi bangun ruang, maka penelitian ini bertujuan untuk mengeksplorasi penggunaan GeoGebra dalam memahami konsep bangun ruang.

\section{METODE}

Penelitian ini menggunakan metode penelitian kualitatif dengan teknis studi kasus. Data yang dikumpulkan dalam penelitian berupa kata-kata yang diperoleh melalui hasil wawancara, gambar hasil pekerjaan subjek dalam menyelesaikan masalah matematika untuk mendapatkan gambaran mengenai tingkah laku subjek. Deskripsi analisis data dan interpretasi makna temuan menggunakan analisis teks. Penelitian yang memiliki karakteristik seperti ini merupakan penelitian kualitatif (Creswell, 2012; Fraenkel \& Wallen, 2006).

Dalam melakukan penelitian, langkah awal yang dilakukan adalah menyusun instrumen wawancara seperti membuat soal yang digunakan untuk meneliti kemampuan dan pemahaman subjek, menyusun pedoman wawancara dan menyiapkan instalasi program GeoGebra.

Sementara itu, pengumpulan data dilakukan dengan mengumpulkan hasil kerja subjek terhadap soal yang telah diberikan dan juga dari hasil tes wawancara yang dilakukan setelah pemberian soal tertulis kepada subjek. Pemberian soal dilakukan untuk mengetahui kemampuan dan pemahaman subjek terhadap konsep bangun ruang. Sedangkan tes wawancara dilakukan dengan tujuan untuk mengklarifikasi jawaban subjek. Pengumpulan data dilakukan dengan teknik wawancara dan mengumpulkan data-data secara deskriptif. Adapun soal yang digunakan dalam penelitian ini dapat dilihat pada Gambar 1. 


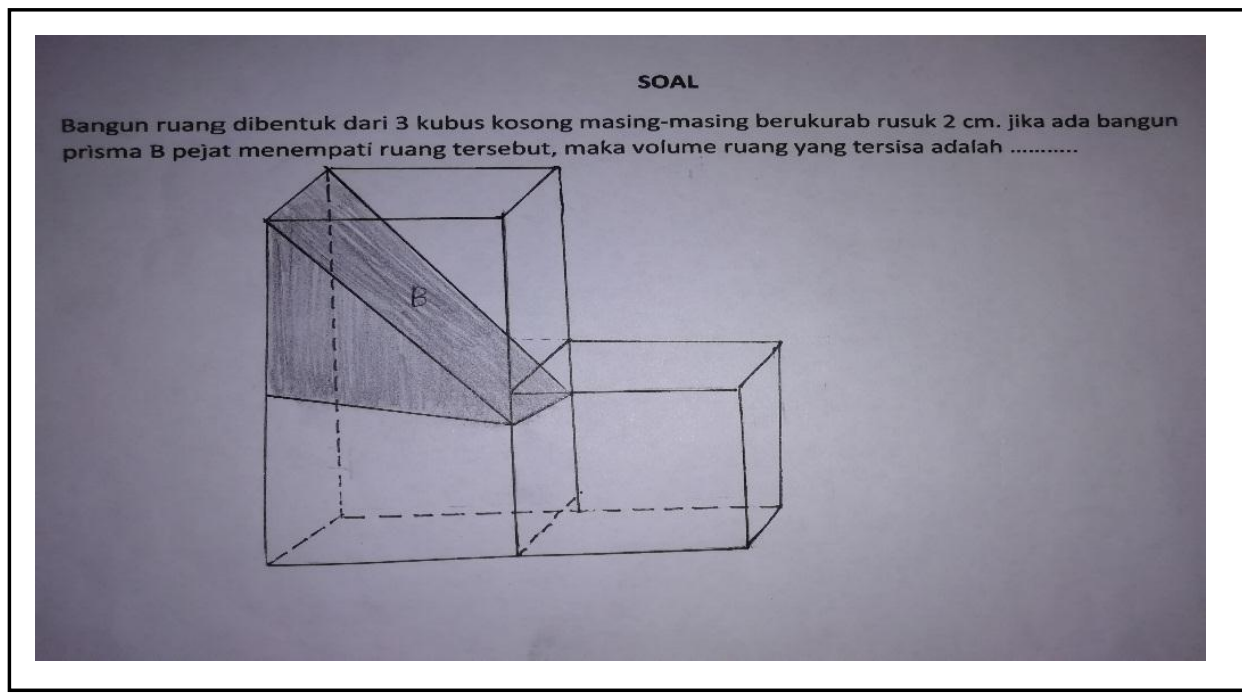

\section{Gambar 1. Soal Bangun Ruang}

Pemilihan subjek yang menggunakan teknik purposive sampling, dimana subjek terpilih adalah siswa di SD kelas VI yang telah menerima materi bangun ruang kubus dan mengalami kesulitan dalam memahaminya. Penelitian berlangsung selama bulan Desembar 2019. Adapun langkah-langkah penelitian secara keseluruhan dapat dilihat pada Gambar 2.

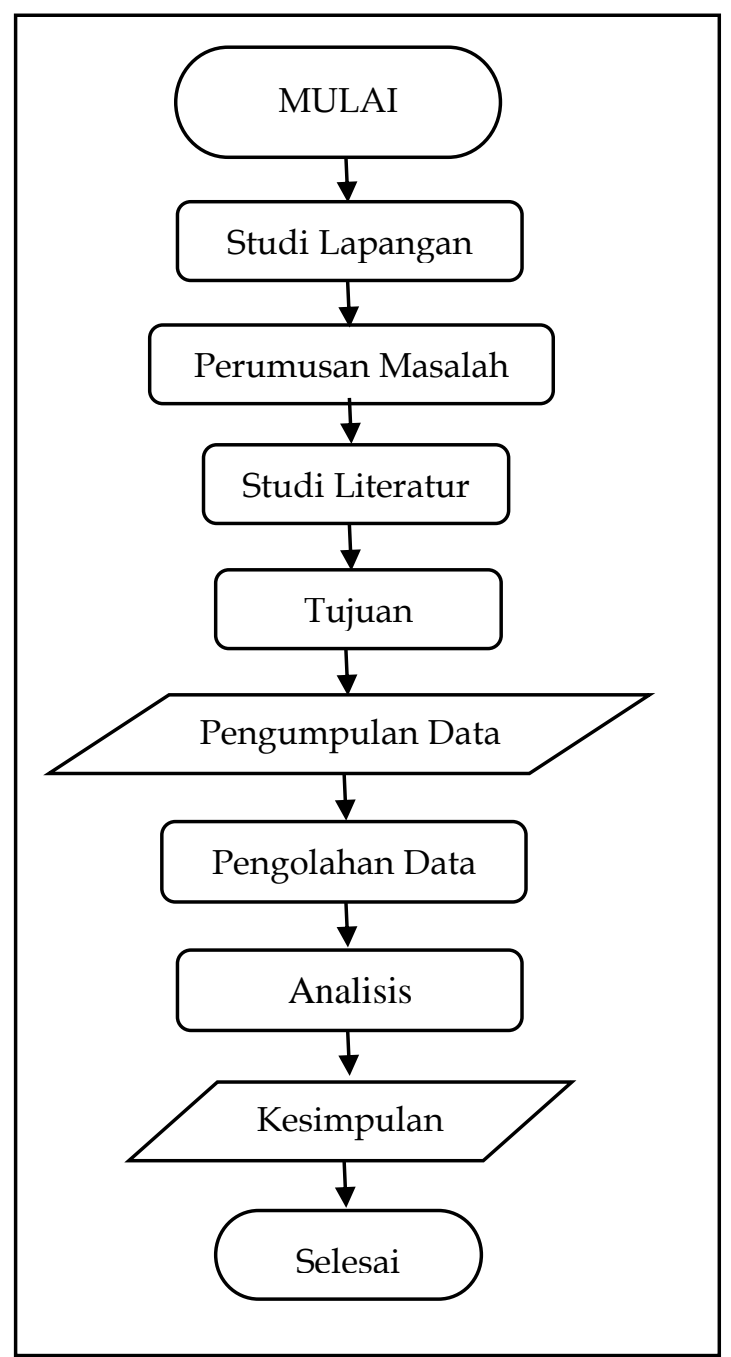

Gambar 2. Alur Kegiatan Penelitian 


\section{HASIL DAN PEMBAHASAN}

Hasil pekerjaan subjek terhadap pemahaman materi Bangun Ruang dapat dilihat pada gambar 3.

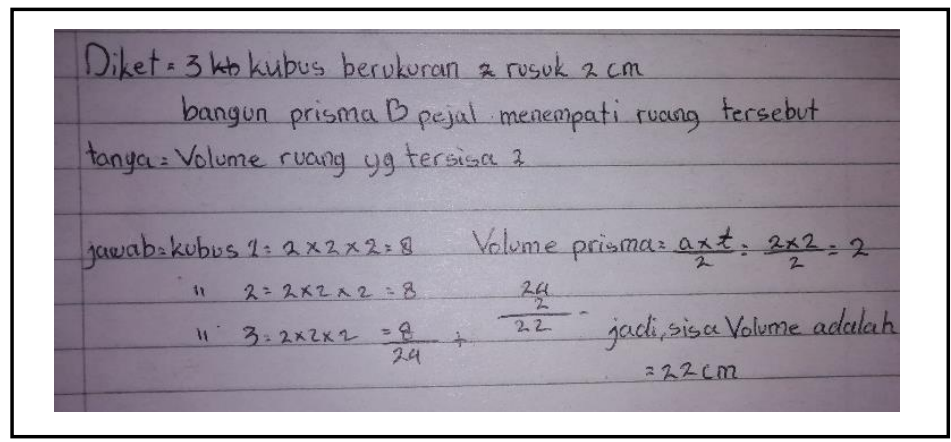

Gambar 3. Hasil Pekerjaan Subjek

Tampak pada pekerjaan subjek dapat dinilai bahwa subjek memahami maksud dari soal tersebut. Hal ini diperkuat dengan hasil wawancara berikut:

P: "Apakah yang ditanyakan dalam soal?"

$\mathrm{S}$ : "volume ruang yang tersisa"

P : "Apakah anda memahami maksud dari soal?"

S: "iya, saya paham"

Memang dalam pemahaman soal subjek memahaminya, tetapi subjek lupa dengan rumus bangun ruang prisma. Akibat ketidak tahuannya membuat subjek mengerjakan soal dengan lama. Hal ini juga berdampak pada hasil akhir dan saat ditanya oleh peneliti, subjek tidak yakin dengan hasil pekerjaannya. Hal ini diperkuat dengan hasil wawancara berikut:

P: "Apakah anda yakin dengan hasil pekerjaaan anda?"

S: "Tidak."

P : "Apa yang membuat anda tidak yakin dengan hasil pekerjaan anda sendiri?"

S : "Saya paham maksud soal tersebut, tetapi yang membuat saya tidak yakin karena saya lupa bagaima rumus untuk menghitung volume prisma."

Pada tahap ini, peneliti menilai bahwa subjek tidak memahami betul konsep bangun ruang. Hal ini dapat dilihat dari hasil wawancara, bahwa subjek tidak mengetahui cara lain untuk menyelesaikan soal Bangun Ruang. Hasil wawancara subjek dapat dilihat sebagai berikut:

P : "Apakah anda tau cara lain, selain yang anda gunakan?"

S: "Tidak"

P: "Apakah guru di sekolah hanya memakai media papan?"

S : "Iya."

P: "Apakah anda tahu, cara mengerjakan soal ini dengan menggunakan cara lain?"

$\mathrm{S}$ : "Tidak, karena guru saya hanya mengajarkan cara itu di sekolah."

Pada tahap ini peneliti menjelaskan mengenai konsep bangun ruang seperti rusuk dan sisi dengan berbantuan GeoGebra. 


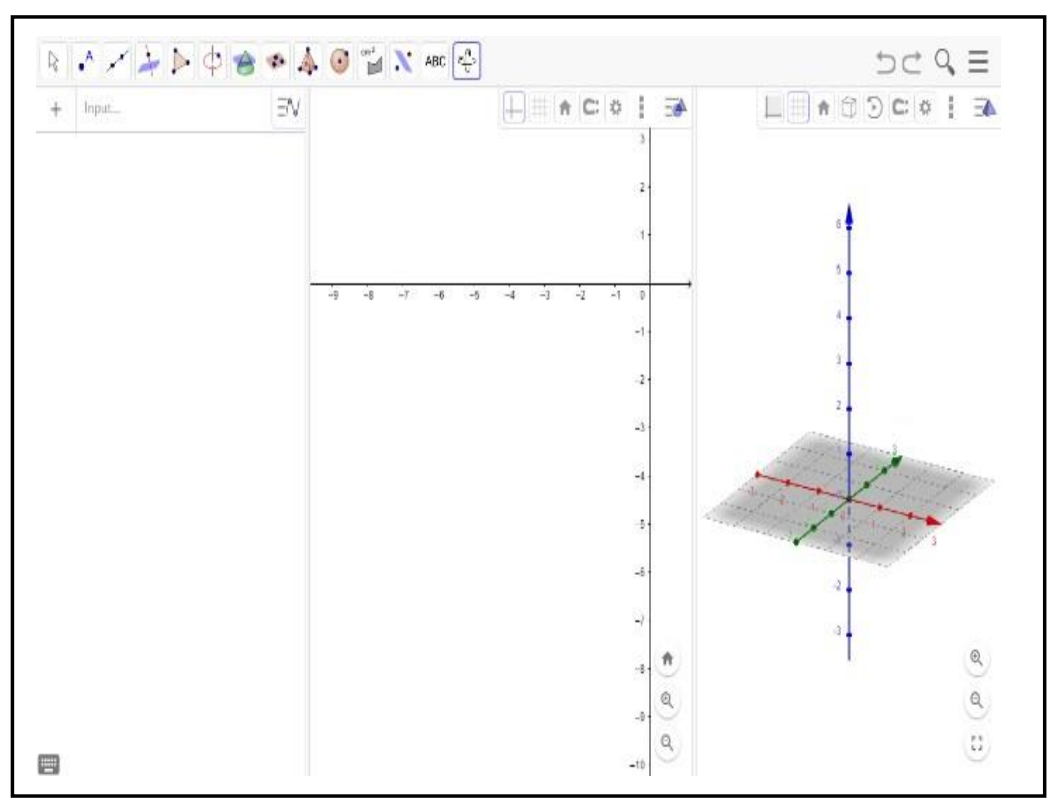

Gambar 4. Tampilan grafik 3D pada GeoGebra

Grafik diatas merupakan tampilan grafik 3D. Peneliti menjelakan bagaimana munculnya grafik 3D. Peneliti membuka menu view kemudian memilih menu 3D, maka muncullah grafik 3D seperti gambar tersebut.

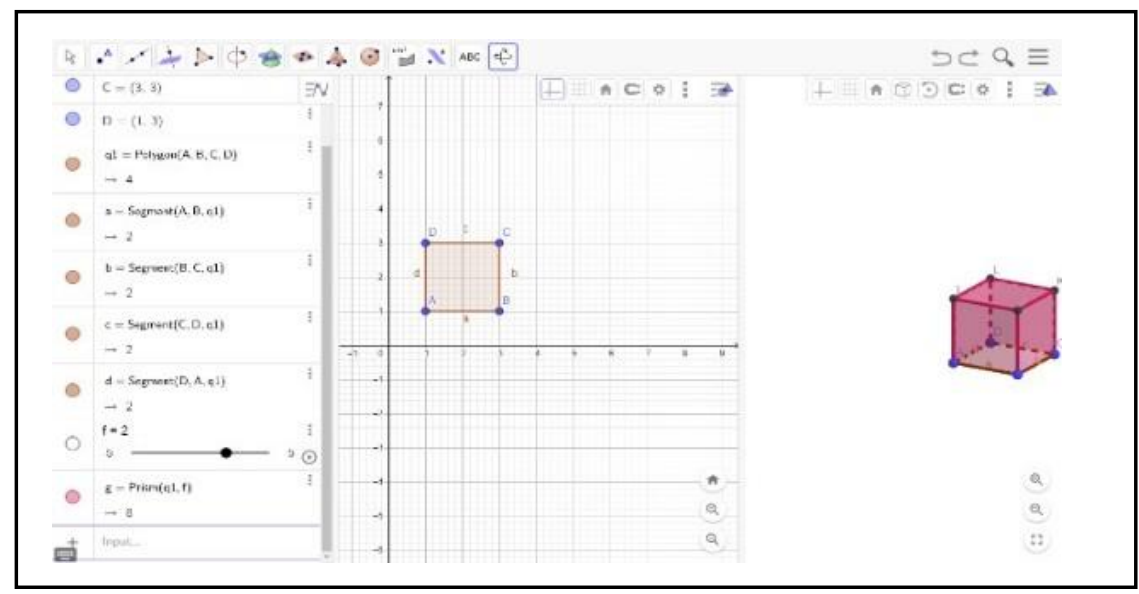

Gambar 5. Gambar 3D Bangun Ruang Kubus pada GeoGebra

Selanjutnya, peneliti menjelaskan untuk menampilkan kubus 3D. Disini peneliti menekan menu point dan memberi titik pada graphics di 4 letak yang berbeda dengan ukuran yang sama. Kemudian, memilih menu extrude to prism dan meletakkan cursor pada polygon yang sudah dibuat, lalu akan muncul tabel attitude yang dapat peneliti tulis sebagai ukuran kubus, muncullah kubus 3D. Peneliti melakukan hal yang sama untuk membuat kubus, agar sesuai dengan soal. 


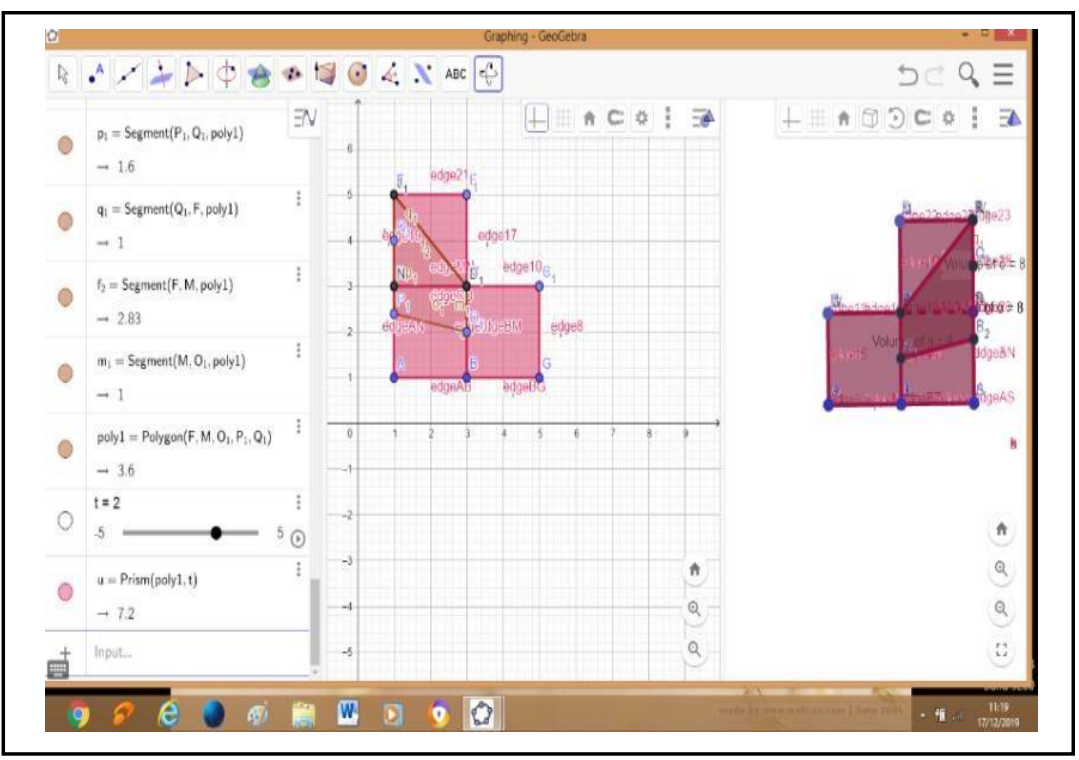

Gambar 6. Tampilan Volume Kubus pada GeoGebra

Untuk menampilkan tampilan seperti pada gambar 5, dapat menekan pada kolom input dan menuliskan "cube(point, point)". Jika ingin mengetahui volume kubus tersebut, peneliti menekan menu angle, memilih volume dan menekan cursor pada daerah kubus, maka volume kubus akan muncul.

Setelah peneliti menjelaskan mengenai konsep dasar bangun ruang didapat perbedaan pemahaman subjek sebelum dan sesudah mengenal GeoGebra. Perbedaan ini dapat dilihat pada Tabel 1.

Tabel 1. Perbedaan Pemahaman Subjek pada Materi Bangun Ruang Sebelum dan Sesudah Mengenal GeoGebra

\begin{tabular}{lll}
\hline Materi & Sebelum Mengenal GeoGebra & Sesudah Mengenal GeoGebra \\
\hline Prisma & Subjek menganggap prisma sama & Subjek dapat membedakan prisma \\
& dengan segitiga & dengan segitiga \\
Sisi & Subjek menghafal banyaknya sisi & Subjek mengetahui dan mampu \\
& prisma & menunjukkan semua sisi pada prisma \\
Rusuk & Subjek menganggap jumlah rusuk & Subjek mengetahui bahwa jumlah rusuk \\
& semua prisma sama & $\begin{array}{l}\text { prisma berbeda dan bergantung pada } \\
\text { bentuk alas }\end{array}$ \\
& & \\
\hline
\end{tabular}

Setelah subjek paham konsep dasar bangun ruang, subjek menjadi bisa mengerjakan soal bangun ruang pada gambar 1 . Adapun hasil pekerjaan subjek, setelah memahami GeoGebra dapat dilihat pada Gambar 7. 


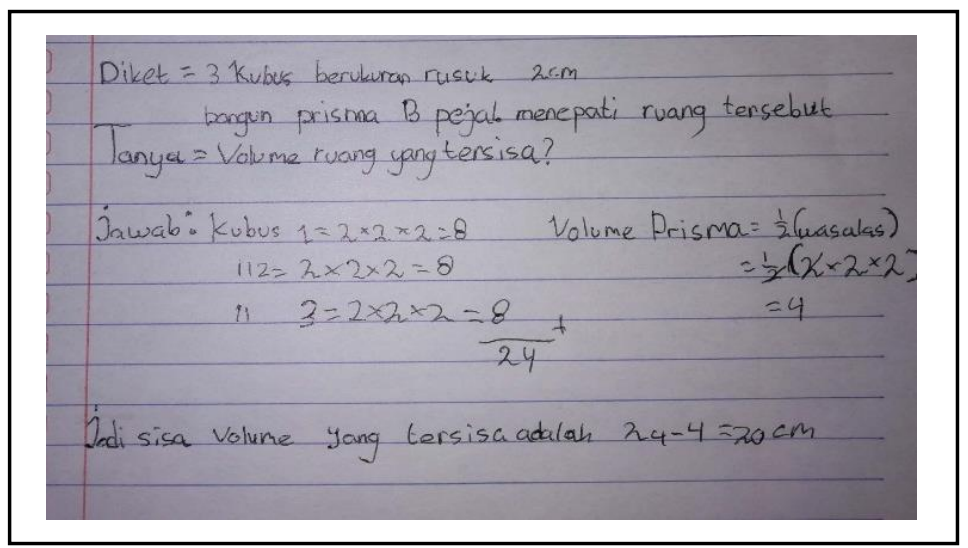

Gambar 7. Hasil Pekerjaan Subjek

\section{SIMPULAN}

Hasil penelitian menunjukkan bahwa subjek lebih mudah memahami konsep materi bangun ruang dengan berbantuan GeoGebra, karena dengan menggunakan GeoGebra subjek dapat melihat bangun ruang secara 3D.

\section{UCAPAN TERIMA KASIH}

Ucapan terima kasih terutama ditujukan kepada seluruh dosen dan staff Laboratorium Terpadu Fakultas Keguruan dan Ilmu Pendidikan, Universitas Islam Malang yang telah memfasilitasi pelaksanaan kegiatan penelitian ini.

\section{DAFTAR PUSTAKA}

Aryasuta, Eka, I. W., \& Sukew, G. (2014). Pengaruh Model Pembelajaran Berbasis Masalah Dengan Media Pembelajaran Berbantuan GeoGebra Terhadap Prestasi Belajar Matematika Siswa Ditinjau Dari Tingkat Ketangguhan Siswa. E-Jurnal Program Pascasarjana Univeritas Pendidikan Ganesha, 3(1).

Creswell, J., \& W. (2012). Research Design Pendekatan Kualitatif, Kuantitatif and Mixed. Yogyakarta: Pustaka Belajar.

Depdiknas. (2006). Permendiknas No 22 Tahun 2006 Tentang Standar Isi. Jakarta: Depdiknas.

Erleni, \& Fitri, T. A. (2015). Rancang Bangun Alat Bantu Ajar Matematika pada Materi Bangun Ruang Berbasis Multimedia ( Study Kasus SMP Negeri 01 Bangkinang Seberang). SATIN - Sains dan Teknologi Informasi, Vol. 1, No. 1, Juni, 10.

Fraenkel, J., R, \& Wallen, N. E. (2006). How to Design and Evaluate Research In Education. New York: McGraw-Hill.

Hohenwater, M. Z. (2008). The Strength of The Community: How GeoGebra Can Inspire Technology Integration in Mathematics Teaching. InspMSOR Connections Vol 9 No.2 May-July 2009,pp, 9(2).

Japa, N., Suarjana, \& Widiana. (2017). MEDIA GEOGEBRA DALAM PEMBELAJARAN MATEMATIKA. International Journal of Natural Science and Engineering. Vol.1(2) pp. 40-47., 41. 
Kusuma, A. B., \& Utami, A. (2017). Penggunaan Program Geogebra dan Casyopee dalam Pembelajaran Geometri Ditinjau Dari Motivasi Belajar Siswa. Jurnal Mercumatika Vol. 1 No. 2 April, 120-124.

Subarinah, S. (2006). Inovasi Pembelajaran Matematika SD. Depdiknas. 